\title{
Addition of Various Cellulosic Components to Bacterial Nanocellulose: A Comparison of Surface Qualities and Crystalline Properties
}

\author{
Won Yeong Bang ${ }^{1,2 \dagger}$, Dong Hyun Kim ${ }^{3 \dagger}$, Mi Dan Kang ${ }^{1}$, Jungwoo Yang ${ }^{2}$, Taelin Huh ${ }^{4}$, \\ Young Woon Lim ${ }^{5}$, and Young Hoon Jung ${ }^{1 *}$
}

${ }^{1}$ School of Food Science and Biotechnology, Kyungpook National University, Daegu 41566, Republic of Korea ${ }^{2}$ Ildong Bioscience, Pyeongtaek 17957, Republic of Korea

${ }^{3}$ Department of Biotechnology, Graduate School, Korea University, Seoul 02841, Republic of Korea

${ }^{4}$ School of Life Science and Biotechnology, Kyungpook National University, Daegu 41566, Republic of Korea

${ }^{5}$ School of Biological Sciences and Institution of Microbiology, Seoul National University, Seoul 08826, Republic of Korea

Bacterial nanocellulose (BNC) is a biocompatible material with a lot of potential. To make BNC commercially feasible, improvements in its production and surface qualities must be made. Here, we investigated the in situ fermentation and generation of BNC by addition of different cellulosic substrates such as Avicel and carboxymethylcellulose (CMC) and using Komagataeibacter sp. SFCB22-18. The addition of cellulosic substrates improved BNC production by a maximum of about 5 times and slightly modified its structural properties. The morphological and structural properties of BNC were investigated by using Fourier transform-infrared spectroscopy (FT-IR), scanning electron microscopy and X-ray diffraction. Furthermore, a type-A cellulose-binding protein derived from Clostridium thermocellum, CtCBD3, was used in a novel biological analytic approach to measure the surface crystallinity of the BNC. Because Avicel and CMC may adhere to microfibrils during BNC synthesis or crystallization, cellulose-binding protein could be a useful tool for identifying the crystalline properties of BNC with high sensitivity.

Keywords: Bacterial nanocellulose, Komagataeibacter, cellulose-binding protein, Avicel, carboxymethyl cellulose, fermentation

Received: June 23, 2021 Accepted: July 21, 2021

First published online: July 23, 2021

*Corresponding author Phone: +82-53-950-5777 Fax: +82-53-950-6772 E-mail:younghoonjung@ knu.ac.kr

${ }^{\dagger}$ These authors contributed equally to this work.

pISSN 1017-7825 eISSN 1738-8872

Copyright $\odot 2021$ by the authors. Licensee KMB. This article is an open access article distributed under the terms and conditions of the Creative Commons Attribution (CC BY) license.

\section{Introduction}

Cellulose, which is made up of a linear chain of glucose molecules linked by $\beta$-1,4-glycosidic linkages, is highly representative of renewable polymers in nature [1]. Cellulose is a biocompatible, biodegradable, and renewable substance that has received a great deal of attention, not only as a biopolymer capable of serving as an alternative to plastics in the chemical industry, but also as a medical material for tissue engineering and carrying drugs in the medical industry [2-6]. Furthermore, the derivatization of the cellulose surface can considerably improve its functionalities, broadening the applications of cellulose in numerous industries [7-10].

Lignocellulosic biomass is the most representative source of cellulose; however, because hemicellulose and lignin are present, severe and complex pretreatment steps with bleaching are required in order to achieve pure cellulose, resulting in high operating costs. As a result, microbial production of pure cellulose (i.e., bacterial nanocellulose; $\mathrm{BNC}$ ) has received a lot of attention as a potential alternative $[2,3,11-13]$. The use of bacteria to produce cellulose has a number of advantages, such as high purity and high specific surface area. For example, $\mathrm{BNC}$ has been widely utilized as a source of food, like Nata de coco, or as a food additive used for dietary fiber or as a thickener [14-16].

To enhance the applicability of BNC, significant cost reduction should be achieved by increasing BNC production as well as by specializing in the properties of BNC. There have been many studies aimed at obtaining BNC by using a novel superior microorganism or by optimizing fermentation conditions $[17,18]$. Meanwhile, incorporating different additives including bio-derived polymers also showed beneficial effects on BNC production (Table 1) [19-25]. For example, carboxymethyl cellulose, a soluble form of cellulose, has generally provided an increase in BNC production yield, as well as modifying the cellulose properties, such as crystallinity. Meanwhile, various approaches to measuring the crystallinity of cellulose have been investigated, and recent studies showed that cellulose-binding protein (CBD) may become a more sensitive means of measuring 
Table 1. Literature review regarding bacterial nanocellulose incorporating different additives.

\begin{tabular}{lllll}
\hline \multicolumn{1}{c}{ Strains } & \multicolumn{1}{c}{ Additives } & Concentrations & \multicolumn{1}{c}{ Target objectives } & Ref. \\
\hline Gluconacetobacter xylinus 53582 & CMC, Pectin, Gelatin, & $1 \%, 3 \%, 5 \%$ & BC production & \\
& Corn starch & & & \\
G. xylinus (BCRC 12335) & CMC & $0-1 \%$ & Rehydration properties & {$[19]$} \\
G. xylinus (TISTR 975) & CNC & $0 \%, 0.25 \%, 0.5 \%$ & Colloidal stability & {$[21]$} \\
Acetobacter xylinum x-2 & Hydroxyapatite & 1.5 times (v/v) & Artificial bones and scaffolds & {$[22]$} \\
A. xylinum & PVA & $5 \%$ & Optical transparent films & {$[23]$} \\
A. xylinum (ATCC 700178) & CMC, Avicel, & $0.2 \%, 0.5 \%$ & BC production & {$[24]$} \\
G. xylinus (BRC- 5) & Sodium alginate, Agar & & & Wound dressing \\
\hline
\end{tabular}

${ }^{\star}$ PVA: Polyvinyl alcohol, CMC: Carboxymethyl cellulose, CNC: Cellulose nanocrystal

crystallinity changes in cellulose [26, 27]. Since BNC is known to be one of the most crystalline polymers, measuring changes in the crystallinity of modified BNC could become a vital clue in proposing applications. To date, no studies have been investigating the crystallinity of BC using CBD.

In this study, we studied the effects of adding different cellulosic substrates on the synthesis and characteristics of BNC using Komagataeibacter sp. SFCB22-18 isolated from ripened persimmons [17]. The changes in various structural properties were investigated via scanning electron microscopy (SEM), Fourier-transform infrared (FTIR) spectroscopy, X-ray diffraction (XRD), and the use of a type-A cellulose-binding protein derived from Clostridium thermocellum (CtCBD3). This study provides fundamental information on the effects of the addition of different types of cellulosic substrates during fermentation upon the production and structural modification of BNC.

\section{Materials and Methods}

Strain and Chemicals

Komagataeibacter sp. SFCB22-18, as obtained from ripened persimmons, was used in this study [17]. The strain was stored at $-80^{\circ} \mathrm{C}$ in a $50 \%(\mathrm{v} / \mathrm{v})$ glycerol solution. Carboxymethylcellulose (CMC) and Avicel were purchased from Sigma-Aldrich (USA). Komagataeibacter sp. SFCB22-18 was routinely cultivated in Hestrin-Schramm modified (HSM) medium containing $30 \mathrm{~g}$ glucose, $25 \mathrm{~g}$ yeast extract, $2.7 \mathrm{~g} \mathrm{Na}_{2} \mathrm{HPO}_{4}, 2.4 \mathrm{~g}$ acetic acid, and $5 \mathrm{~g}$ ethanol per liter. For bacterial cellulose (BC) production, an aliquot $(1 \mathrm{ml}$ ) of the cell medium grown over 3 days was added to $100 \mathrm{ml}$ of $\mathrm{HSM}$ medium in a $250-\mathrm{ml}$ flask and incubated at $30^{\circ} \mathrm{C}$ for 7 days without shaking. For in situ production of BC, various concentrations, such as $0.1 \%(\mathrm{w} / \mathrm{v})$ and $1 \%$ of CMC and Avicel, were added to the HSM medium.

\section{Production and Purification of BNC}

BNC pellicles were produced and purified by following previous study [17] with slight modification. The pellicles floating on the surface of the culture medium were collected, immersed in $0.1-\mathrm{N} \mathrm{NaOH}$ at $80^{\circ} \mathrm{C}$ for $2 \mathrm{~h}$ to remove impurities such as bacteria cells and other medium components, and then washed with distilled water until the filtrate's $\mathrm{pH}$ became neutral. The total solids content of the washed $\mathrm{BC}$ samples was measured by drying at $45^{\circ} \mathrm{C}$ for $72 \mathrm{~h}$ using a drying oven (BF-135C, BioFree, Korea). For further analysis, the $\mathrm{BC}$ was freeze-dried using a freeze dryer (Lyophilizer, IlShinBioBase Co., Korea) and stored at $4^{\circ} \mathrm{C}$.

\section{Scanning Electron Microscopy (SEM) and Fourier Transform-Infrared (FT-IR) Spectroscopy Analysis}

The lyophilized BNC samples were analyzed by SEM and FT-IR by following previous study [17] with slight modification.

SEM: The lyophilized BC samples were coated with a thin platinum film. The surface morphology of the BC samples was taken at an accelerating voltage of $16 \mathrm{kV}$ using a field-emission scanning electron microscope (FESEM, SU8220; Hitachi, Japan).

FT-IR: The FT-IR spectra of lyophilized BC samples were analyzed using a Nicolet iS5 FT-IR Spectrometer (Thermo Scientific, USA) in the range of $4,000-450 \mathrm{~cm}^{-1}$ in the transmission mode. The spectra were recorded at a resolution of $4 \mathrm{~cm}^{-1}$ with 16 scans. The data were analyzed using OMNIC software (OMNIC v.9.7.46 firmware version 2.03; Thermo Scientific).

\section{X-Ray Diffractometer (XRD) Analysis}

To investigate the crystallinity of the lyophilized BNC, X-ray diffractometer (D/Max-2500, Rigaku, Japan) analysis was performed using a cooper $\mathrm{X}$-ray source. The diffracted radiation was measured in the range $2 \theta=5^{\circ}$ to $50^{\circ}$, and the crystallinity index of cellulose, Crl, was calculated through the following equation [28]:

$$
\operatorname{Crl}(\%)=\left[\left(\mathrm{I}_{200}-\mathrm{I}_{\mathrm{am}}\right) / \mathrm{I}_{200}\right] \times 100,
$$

where $\mathrm{I}_{200}$ represents the total intensity (i.e., crystalline region) at approximately $2 \theta=22.7^{\circ}$ and $\mathrm{I}_{\mathrm{am}}$ represents the baseline intensity (i.e., amorphous region) at approximately $2 \theta=18^{\circ}$. 
Analysis of Protein Binding to the Crystalline Region of Cellulose

Quantitative analysis of the surface crystallinity of BNC was indirectly measured using CtCBD3 (UniProtKB: Q06851), a cellulose-binding protein derived from C. thermocellum (ATCC 27405), by following previous study [29] with slight modification. The CtCBD3 gene was cloned to Escherichia coli BL21(DE3) using the pET-21a. The strain harboring the $C t \mathrm{CBD} 3$ gene was grown in Luria-Bertani broth (BD, USA) containing $50 \mu \mathrm{g} / \mathrm{ml}$ of ampicillin at $37^{\circ} \mathrm{C}$. When the optical density reached 0.5 , isopropyl- $\beta$-D-thiogalactopyranoside $(1 \mathrm{mM})$ was added and then incubated at $37^{\circ} \mathrm{C}$ for $4 \mathrm{~h}$. After centrifugation at $10,000 \times g$ at $4^{\circ} \mathrm{C}$ for $30 \mathrm{~min}$, re-suspended cells in $50 \mathrm{mM}$ Tris- $\mathrm{HCl}(\mathrm{pH} 8.0)$ were disrupted by sonication and the supernatant was centrifuged at $10,000 \times g$ at $4^{\circ} \mathrm{C}$ for $30 \mathrm{~min}$. The recombinant enzyme was purified using Ni-NTA agarose (Qiagen, Germany) and $50 \mathrm{mM}$ of imidazole. For analysis of binding affinity of $C t \mathrm{CBD} 3 \mathrm{on} \mathrm{BC}$ samples, $5.6 \mathrm{nM}$ of $C t \mathrm{CBD} 3$ was incubated with $1 \mathrm{mg}$ of each BC sample in a $50 \mathrm{mM}$ potassium phosphate buffer $(\mathrm{pH} 7.0)$ with a total reaction volume of $500 \mu \mathrm{l}$, for $12 \mathrm{~h}$ at $4^{\circ} \mathrm{C}$. Subsequently, the reaction mixture was centrifuged at $13,000 \times g$ for 5 min to separate unbounded protein from the BC sample. Only unbound protein in the supernatant was quantified through the bicinchoninic acid assay, and the amount of bound protein was calculated by subtracting the amount of unbound protein from the total protein amount.

\section{Results and Discussion \\ Effect on BNC Production}

The impact of various cellulosic component additions upon BNC synthesis by Komagataeibacter sp. SFCB22-18 was initially examined. Because of the unique physical and chemical properties of Avicel (microcrystalline cellulose made from acid hydrolysis of wood pulp) and carboxymethylcellulose (CMC; cellulose derivatives with carboxymethyl groups at some of the glucopyranose hydroxyl groups), these celluloses are promising candidate materials for use in the food, pharmaceutical, paper, and cosmetic industries [30]. Thus, in this study Avicel and CMC were employed as cellulosic additives for altering BNC properties [31,32]. Avicel and CMC addition showed slight increase in the BNC production (Fig. 1) when compared to the control group (i.e., without additives, $0.4 \mathrm{~g} / \mathrm{l}$ ). With the additions of $0.1 \%$ Avicel and CMC, the Komagataeibacter strain produced $0.5 \mathrm{~g} / \mathrm{l}$ and $0.7 \mathrm{~g} / \mathrm{l}$ of cellulose pellicles, respectively. BNC production increased significantly when the quantities of cellulosic additions climbed to $1 \%$. Particularly, the addition of $1 \%$ CMC resulted in the greatest BNC production of $2.0 \mathrm{~g} / \mathrm{l}$, which is equivalent to 5 times higher than in the control group. This increase might be because of the proper incorporation (or adsorption) of additives and reduction in crystallinity, which is a rate-limiting step during BNC production [31-33]. Meanwhile, Avicel did not show much improvement in BNC production because Avicel is less soluble than CMC [24]. Without optimization of reaction conditions, it was again proved that soluble additives may give more beneficial effects on production of BNC [31-33].

\section{Morphological and Structural Properties of Modified BNC}

SEM was used to examine the morphological structures of BNC with and without cellulosic additives (Fig. 2). In the pure BNC, thread-like, parallel stacked cellulose bundles with large clumps by aggregation were detected. However, the aggregates were not observable in modified BNC, which could be due to adsorption of additives on BCN surfaces [34-36]. This is most likely due to the constraints of intermolecular interactions between cellulose fibrils, including hydrogen bonding, the van der Waals force, and the electrostatic interactions, all of which help to stabilize the highly organized BC structure [37]. Accordingly, CMC-modified BNC had fibers that were somewhat longer than what Avicel-modified BNC had, probably due to repulsive force. Hence, BNC's structural morphology and crystalline characteristics were effectively altered by the incorporation of cellulosic additive. The FT-IR spectra (Figs. 3A-3B) of pure BNC and modified BNC revealed a broad $\mathrm{OH}$ peak stretching in the range of $3,500-3,000 \mathrm{~cm}^{-1}$ and $\mathrm{C}-\mathrm{O}-\mathrm{C}$ stretching at about $1,160 \mathrm{~cm}^{-1}$, as reported in a typical BNC spectrum [38, 39]. Additional peaks of $1,160 \mathrm{~cm}^{-1}$ (C-O-C stretching) and 1,035-1,060 $\mathrm{cm}^{-1}$ (C-O stretching) have been found in pure BNC. In Avicel- and CMC-altered BNC, the peak intensity at 3,500-3,000 $\mathrm{cm}^{-1}$ increased in comparison with that

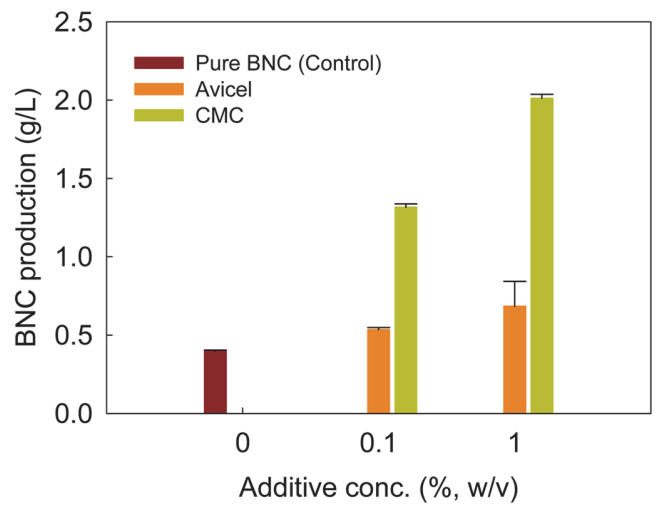

Fig. 1. Production of bacterial nanocellulose by Komagataeibacter sp. SFCB22-18 in HSM medium containing different concentrations of Avicel and CMC. This experiment was performed in triplicate. 
A

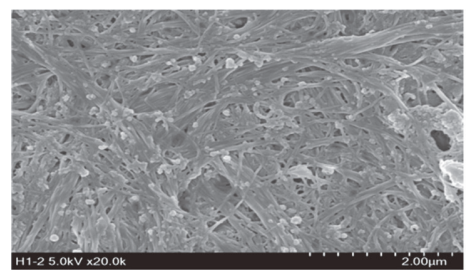

B

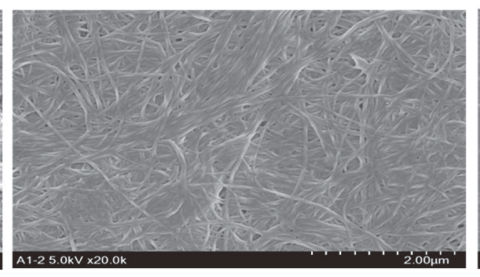

C

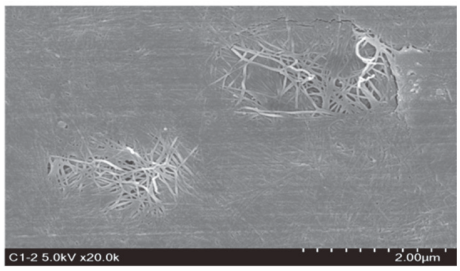

Fig. 2. Scanning electron microscopy images of bacterial nanocellulose produced by Komagataeibacter sp. SFCB22-18 (A) without additives as a control; (B) with $1 \%(w / v)$ Avicel; and (C) with $1 \%(w / v) ~ C M C$.

in pure BNC. In addition, in Avicel-altered BNC, the peak intensities at around 1,620-1,650 $\mathrm{cm}^{-1}$ (OH bending) increased, showing stronger adsorption of water molecules to BNC. This may be due to either the inhibition of $\mathrm{BNC}$ crystallization by reducing the degree of polymerization (DP) of the modified BNC [40] or the exposure of more $\mathrm{OH}$ groups by disruption of intermolecular interactions in BNC [41]. In CMC-modified BNC, strong absorption peaks at 1,572 $\mathrm{cm}^{-1}$, (i.e., corresponding to the carboxyl group) [41] were well integrated (or adsorbed) on pure BNC.

\section{Degree of Crystallinity}

The hardness, elasticity, permeability, and reactivity of cellulose may be indirectly reflected in its crystalline properties [42]. Because BNC is one of the most crystalline polymers, determining changes in the crystallinity of modified BNC could be a crucial indication in developing new applications. There has been no research on the crystallinity of BNC utilizing CBD yet. According to a prior study, crystallinity or BNC is negatively associated to polymerization of glucose [43]. As a result, we used XRD and crystalline cellulose-binding protein to examine and evaluate the crystalline characteristics of BNC modified by the inclusion of cellulosic additives.

XRD was used to determine the crystallinity of BNC after the various cellulosic components were added (Figs. 3C-3D). The XRD pattern of pure BNC revealed highly strong diffraction peaks at $2 \theta=22.7^{\circ}$ (primary peak), $14.5^{\circ}$, and $16.8^{\circ}$, corresponding to cellulose I $\alpha$, which is crystalline cellulose that is naturally formed [44]. The Avicel- and CMC-altered BNC showed similar patterns to cellulose I. However, as the concentrations of
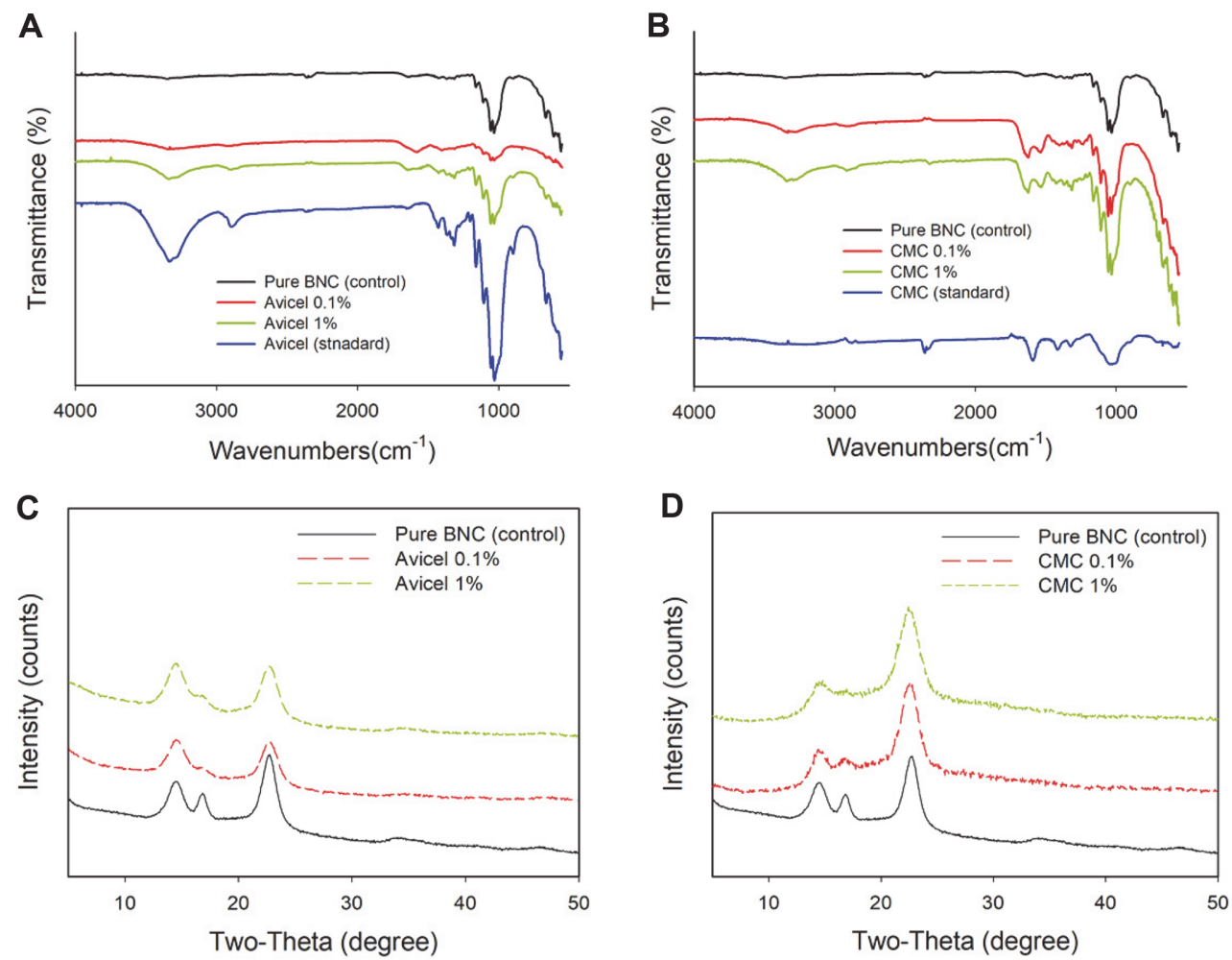

Fig. 3. Fourier transform-infrared spectroscopy analysis and $\mathrm{X}$-ray diffraction patterns of bacterial nanocellulose produced by Komagataeibacter sp. SFCB22-18 with (A, C) Avicel and (B, D) CMC. 
Table 2. Summary of the crystallinities of bacterial nanocellulose incorporating different concentrations of cellulosic additives.

\begin{tabular}{|c|c|c|c|c|}
\hline & & $\operatorname{Crl}(\%)$ & TCI (\%) & Relative value of CBM binding (\%) \\
\hline $\mathrm{BC}$ & & 77.6 & 0.994 & 100 \\
\hline Avicel & & 74.1 & 0.991 & 110.8 \\
\hline \multirow[t]{2}{*}{$\mathrm{CMC}$} & & 1.2 & 0.999 & 17.5 \\
\hline & Additive conc. (\%) & $\operatorname{Crl}(\%)$ & TCI (\%) & Relative value of CBM binding (\%) \\
\hline \multirow[t]{2}{*}{$\mathrm{BC}+$ Avicel } & 0.1 & 72.2 & 0.993 & 243.3 \\
\hline & 1.0 & 73.4 & 0.969 & 233.0 \\
\hline \multirow[t]{2}{*}{$\mathrm{BC}+\mathrm{CMC}$} & 0.1 & 69.2 & 0.988 & 177.8 \\
\hline & 1.0 & 70.2 & 0.970 & 249.0 \\
\hline
\end{tabular}

${ }^{*}$ BC: Bacterial nanocellulose, CMC: Carboxymethyl cellulose, CrI: Crystallinity index, TCI: Total crystallinity index, CBM: Cellulose binding Module

additives increased, the diffraction peaks at the $2 \theta$ angles of $16.8^{\circ}$ decreased considerably in comparison with pure $\mathrm{BNC}$. This means that the cellulose I structure was transformed to cellulose allomorph, resulting in the conversion of some crystalline structures into amorphous structures by the addition of cellulose components during BNC production $[45,46]$. Furthermore, the addition of Avicel and CMC lowered the crystallinity index of BNC as evaluated by XRD (Table 1); for instance, while pure BNC had a crystallinity of $77.6 \%$, modified BNC had a crystallinity of $69.2-73.4 \%$. When the total crystallinity index (TCI, A1375/A2900 from FT-IR) was calculated after the addition of cellulosic substrates, a slight decrease in TCI values was detected. These findings are consistent with prior studies suggesting that the addition of cellulosic components slightly hinders the crystallization of BNC during synthesis, with the results of increased BNC production or water retention ability (i.e. OH group exposure at FT-IR).

Next, using cellulose-binding protein, the surface accessibility of the crystalline region of BNC was observed. On the basis of the unique molecular recognition ability as to whether the binding region in cellulose is crystalline or amorphous, CBD has been proposed to understand the surface accessibility of cellulosic substrates $[47,48]$. This is the first time that cellulose-binding proteins have been applied to elucidate the morphology of the BNC surface, one of the nano-sized cellulosic materials. Among cellulose-binding proteins, we selected CtCBD3, originating from C. thermocellum ATCC 27405 and belonging to type-A cellulose-binding proteins, which predominantly bind to the crystalline region of cellulose. The amount of bound protein in pure BNC was approximately $1.9 \mathrm{nmol} / \mathrm{mg}$ substrate (Fig. 4). The modified BNC samples showed 1.8-2.5 times higher binding affinities to $\mathrm{CtCBD} 3$ than pure BNC. Because cellulose-binding proteins are often bound to the surface of the cellulose, XRD or FT-IR focuses on the fiber's internal structure and bulk qualities [26], and the results may differ from XRD results. Therefore, the increased protein binding in this study indicates that cellulosic additives significantly exposed the crystalline areas of BNC to the surface of modified BNC. This could imply that distinct functional groups existed and were stable on the surface of modified BNC. As a result, adding cellulosic substrates like Avicel and CMC to the BNC during synthesis might effectively change the surface crystallinity of the BNC during fermentation. In summary, because Avicel and CMC may adhere to the surface of microfibrils during the formation or crystallization of BNC, determining the crystalline characteristics of BNC by evaluating binding qualities with cellulose-binding protein could be a viable option [36, 40, 49].

To summarize, cellulosic substrates with varying crystalline characteristics, such as Avicel and CMC, were utilized in this study to boost BNC synthesis and alter its surface crystallinity. XRD and the cellulose-binding

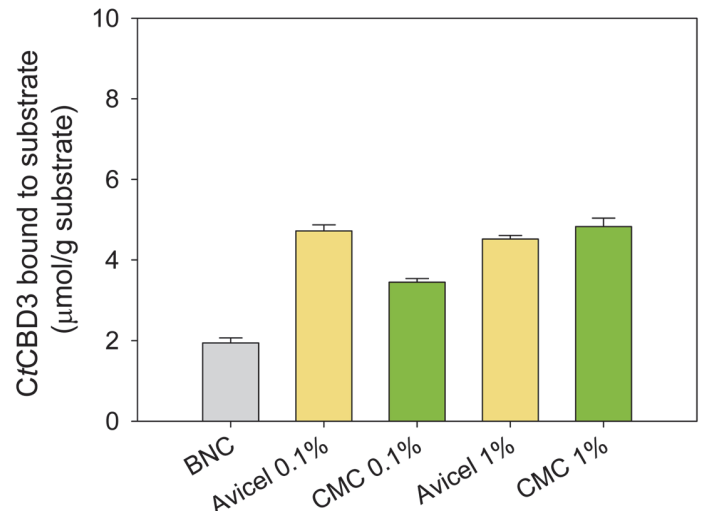

Fig. 4. The binding ability of $C t C B D 3$ to cellulose samples produced by Komagataeibacter sp. SFCB22-18 in an HSM medium containing different concentrations of Avicel and CMC. This experiment was performed in triplicate. 
protein were also used to compare the surface-crystalline characteristics of BNC. The addition of cellulosic substrates significantly improved the BNC production. Furthermore, it was found that the cellulose-binding protein could be used as part of a sensitive technique to measure the crystalline characteristics of BNC. The introduction of the binding protein may become a cost-effective and better alternative than the conventional method.

\section{Acknowledgments}

This work was supported by the Korea Institute of Planning and Evaluation for Technology in Food, Agriculture and Forestry (IPET) through the High Value-added Food Technology Development Program, funded by the Ministry of Agriculture, Food and Rural Affairs (MAFRA)(Grant No. 321028-5). This work was also supported by the Korea Forestry Promotion Institute (Grant No. 2020225C10-2122-AC01).

\section{Conflict of Interest}

The authors have no financial conflicts of interest to declare.

\section{References}

1. Arevalo-Gallegos A, Ahmad Z, Asgher M, Parra-Saldivar R, Iqbal HM. 2017. Lignocellulose: a sustainable material to produce value-added products with a zero waste approach-a review. Int. J. Biol. Macromol. 99: 308-318.

2. Calvino C, Macke N, Kato R, Rowan SJ. 2020. Development, processing and applications of bio-sourced cellulose nanocrystal composites. Prog. Polym. Sci. 103: 101221.

3. Mokhena T John M. 2020. Cellulose nanomaterials: new generation materials for solving global issues. Cellulose 27: 1149-1194.

4. Mokhena T, Sefadi J, Sadiku E, John M, Mochane M, Mtibe A. 2018. Thermoplastic processing of PLA/cellulose nanomaterials composites. Polymers 10: 1363.

5. Sulaeva I, Henniges U, Rosenau T, Potthast A. 2015. Bacterial cellulose as a material for wound treatment: properties and modifications. A review. Biotechnol. Adv. 33: 1547-1571.

6. Svensson A, Nicklasson E, Harrah T, Panilaitis B, Kaplan D, Brittberg M, et al. 2005. Bacterial cellulose as a potential scaffold for tissue engineering of cartilage. Biomaterials 26: 419-431.

7. Badshah M, Ullah H, Khan AR, Khan S, Park JK, Khan T. 2018. Surface modification and evaluation of bacterial cellulose for drug delivery. Int. J. Biol. Macromol. 113: 526-533.

8. Choi SM, Shin EJ. 2020. The nanofication and functionalization of bacterial cellulose and its applications. Nanomaterials $10: 406$.

9. Oprea M, Voicu SI. 2020. Recent advances in composites based on cellulose derivatives for biomedical applications. Carbohydr. Polym. 247: 116683 .

10. van Rie J, Thielemans W. 2017. Cellulose-gold nanoparticle hybrid materials. Nanoscale 9: 8525-8554.

11. Fernandes IdAA, Pedro AC, Ribeiro VR, Bortolini DG, Ozaki MSC, Maciel GM, et al. 2020. Bacterial cellulose: from production optimization to new applications. Int. J. Biol. Macromol. 164: 2598-2611.

12. Gao H, Sun Q, Han Z, Li J, Liao B, Hu L, et al. 2020. Comparison of bacterial nanocellulose produced by different strains under static and agitated culture conditions. Carbohydr. Polym. 227: 115323.

13. Jacek P, Dourado F, Gama M, Bielecki S. 2019. Molecular aspects of bacterial nanocellulose biosynthesis. Microb. Biotechnol. 12: 633649.

14. Yamada Y, Hosono R, Lisdyanti P, Widyastuti Y, Saono S, Uchimura T, et al. 1999. Identification of acetic acid bacteria isolated from Indonesian sources, especially of isolates classified in the genus Gluconobacter. J. Gen. Appl. Microbiol. 45: 23-28.

15. Nguyen VT, Flanagan B, Gidley MJ, Dykes GA. 2008. Characterization of cellulose production by a Gluconacetobacter xylinus strain from Kombucha. Curr. Microbiol. 57: 449-453.

16. Okiyama A, Motoki M, Yamanaka S. 1992. Bacterial cellulose II. Processing of the gelatinous cellulose for food materials. Food Hydrocoll 6: 479-487.

17. Park MS, Jung YH, Oh SY, Kim MJ, Bang WY, Lim YW. 2019. Cellulosic nanomaterial production via fermentation by Komagataeibacter sp. SFCB22-18 isolated from ripened persimmons. J. Microbiol. Biotechnol. 29: 617-624.

18. Du R, Zhao F, Peng Q, Zhou Z, Han Y. 2018. Production and characterization of bacterial cellulose produced by Gluconacetobacter xylinus isolated from Chinese persimmon vinegar. Carbohydr. Polym. 194: 200-207.

19. Dayal MS, Catchmark JM. 2016. Mechanical and structural property analysis of bacterial cellulose composites. Carbohydr. Polym. 144: $447-453$.

20. Chen HH, Chen LC, Huang HC, Lin SB (2011) In situ modification of bacterial cellulose nanostructure by adding CMC during the growth of Gluconacetobacter xylinus. Cellulose 18: 1573-1583.

21. Niamsap T, Lam NT, Sukyai P. 2019. Production of hydroxyapatite-bacterial nanocellulose scaffold with assist of cellulose nanocrystals. Carbohydr. Polym. 205: 159-166.

22. Wan Y.Z, Hong L, Jia SR, Huang Y, Zhu Y, Wang YL, et al. 2006. Synthesis and characterization of hydroxyapatite-bacterial cellulose nanocomposites. Compos. Sci. Technol. 66: 1825-1832.

23. Gea S, Bilotti E, Reynolds CT, Soykeabkeaw N, Peijs T. 2010. Bacterial cellulose-poly (vinyl alcohol) nanocomposites prepared by an in-situ process. Mater. Lett. 64: 901-904.

24. Lee HC, Zhao X. 1999. Effects of mixing conditions on the production of microbial cellulose by Acetobacter xylinum. Biotechnol. Bioprocess Eng. 4: 41-45.

25. Cheng KC, Catchmark JM, Demirci A. 2009. Effect of different additives on bacterial cellulose production by Acetobacter xylinum and analysis of material property. Cellulose 16: 1033-1045.

25. Kim J, Cai Z, Chen Y. 2010. Biocompatible bacterial cellulose composites for biomedical application J. Nanotechnol. Eng. Med. 1: 011006.

26. Kljun A, Benians TA, Goubet F, Meulewaeter F, Knox JP, Blackburn RS. 2011. Comparative analysis of crystallinity changes in cellulose I polymers using ATR-FTIR, X-ray diffraction, and carbohydrate-binding module probes. Biomacromolecules 12: 41214126.

27. Gao S, You C, Renneckar S, Bao J, Zhang YHP. 2014. New insights into enzymatic hydrolysis of heterogeneous cellulose by using carbohydrate-binding module 3 containing GFP and carbohydrate-binding module 17 containing CFP. Biotechnol. Biofuels 7: 24 .

28. Foner H, Adan N. 1983. The characterization of papers by X-ray diffraction (XRD): measurement of cellulose crystallinity and determination of mineral composition. J. Forensic. Sci. Soc. 23: 313-321.

29. Jung YH, Kim IJ, Han JI, Choi IG, Kim KH. 2011. Aqueous ammonia pretreatment of oil palm empty fruit bunches for ethanol production. Bioresour. Technol. 102: 9806-9809. 
30. Benchabane A, Bekkour K. 2008. Rheological properties of carboxymethyl cellulose (CMC) solutions. Colloid. Polym. Sci. $286: 1173$.

31. Lin SP, Liu CT, Hsu KD, Hung YT, Shih TY, Cheng KC. 2016. Production of bacterial cellulose with various additives in a PCS rotating disk bioreactor and its material property analysis. Cellulose 23: 367-377.

32. Cheng KC, Catchmark JM, Demirci A. 2009. Effect of different additives on bacterial cellulose production by Acetobacter xylinum and analysis of material property. Cellulose 16: 1033-1045.

33. Cheng KC, Catchmark JM, Demirci A. 2011. Effects of CMC Addition on bacterial cellulose production in a biofilm reactor and its paper sheets analysis. Biomacromolecules 12: 730-736.

34. Ishida T, Mitarai M, Sugano Y, Shoda M. 2003. Role of water-soluble polysaccharides in bacterial cellulose production. Biotechnol. Bioeng. 83: 474-478.

35. Bae S, Sugano Y, Shoda M. 2004. Improvement of bacterial cellulose production by addition of agar in a jar fermentor. J. Biosci. Bioeng. 97: 33-38.

36. Zhou L, Sun D, Hu L, Li Y, Yang J. 2007. Effect of addition of sodium alginate on bacterial cellulose production by Acetobacter xylinum. J. Ind. Microbiol. Biotechnol. 34: 483.

37. Moon RJ, Martini A, Nairn J, Simonsen J, Youngblood J. 2011. Cellulose nanomaterials review: structure, properties and nanocomposites. Chem. Soc. Rev. 40: 3941-3994.

38. Grande CJ, Torres FG, Gomez CM, Bañó MC. 2009. Nanocomposites of bacterial cellulose/hydroxyapatite for biomedical applications. Acta Biomater. 5: 1605-1615.

39. Auta R, Adamus G, Kwiecien M, Radecka I, Hooley P. 2017. Production and characterization of bacterial cellulose before and after enzymatic hydrolysis. Afr. J. Biotechnol. 16: 470-482.

40. Yamamoto H, Horii F, Hirai A. 1996. In situ crystallization of bacterial cellulose II. Influences of different polymeric additives on the formation of celluloses I $\alpha$ and I $\beta$ at the early stage of incubation. Cellulose $3: 229-242$.

41. Fengel D, Ludwig M. 1991. Possibilities and limits of the FTIR spectroscopy for the characterization of cellulose. Pt. 1: Comparison of various cellulose fibres and bacteria cellulose, Papier (Germany, FR)

42. Park S, Baker JO, Himmel ME, Parilla PA, Johnson DK. 2010. Cellulose crystallinity index: measurement techniques and their impact on interpreting cellulase performance. Biotechnol. Biofuels 3: 10.

43. Haigler CH, Brown RM, Benziman M. 1980. Calcofluor white ST alters the in vivo assembly of cellulose microfibrils. Science 210: $903-906$.

44. Tokoh C, Takabe K, Fujita M, Saiki H. 1998. Cellulose synthesized by Acetobacter xylinum in the presence of acetyl glucomannan. Cellulose 5: 249-261.

45. Ling Z, Chen S, Zhang X, Takabe K, Xu F. 2017. Unraveling variations of crystalline cellulose induced by ionic liquid and their effects on enzymatic hydrolysis. Sci. Rep. 7: 10230.

46. Liu H, Cheng G, Kent M, Stavila V, Simmons BA, Sale KL, et al. 2012. Simulations reveal conformational changes of methylhydroxyl groups during dissolution of cellulose I $\beta$ in ionic liquid 1-ethyl-3-methylimidazolium acetate. J. Phys. Chem. B 116: 8131-8138.

47. Aïssa K, Novy V, Nielsen F, Saddler J. 2018. Use of carbohydrate binding modules to elucidate the relationship between fibrillation, hydrolyzability, and accessibility of cellulosic substrates. ACS Sustain Chem. Eng. 7: 1113-1119.

48. Novy V, Aïssa K, Nielsen F, Straus SK, Ciesielski P, Hunt CG, et al. 2019. Quantifying cellulose accessibility during enzyme-mediated deconstruction using 2 fluorescence-tagged carbohydrate-binding modules. Proc. Natl. Acad. Sci. USA 116: 22545-22551.

49. Huang HC, Chen LC, Lin SB, Hsu CP, Chen HH. 2010. In situ modification of bacterial cellulose network structure by adding interfering substances during fermentation. Bioresour. Technol. 101: 6084-6091. 